\title{
Library Design Strategies to Accelerate Fragment-Based Drug Discovery
}

\section{Troelsen, Nikolaj Sten; Clausen, Mads Hartvig}

\section{Published in:}

Chemistry - A European Journal

Link to article, DOI:

10.1002/chem.202000584

Publication date:

2020

Document Version

Peer reviewed version

Link back to DTU Orbit

\section{Citation (APA):}

Troelsen, N. S., \& Clausen, M. H. (2020). Library Design Strategies to Accelerate Fragment-Based Drug Discovery. Chemistry - A European Journal, 26(50), 11391-11403. https://doi.org/10.1002/chem.202000584

\section{General rights}

Copyright and moral rights for the publications made accessible in the public portal are retained by the authors and/or other copyright owners and it is a condition of accessing publications that users recognise and abide by the legal requirements associated with these rights.

- Users may download and print one copy of any publication from the public portal for the purpose of private study or research.

- You may not further distribute the material or use it for any profit-making activity or commercial gain

- You may freely distribute the URL identifying the publication in the public portal

If you believe that this document breaches copyright please contact us providing details, and we will remove access to the work immediately and investigate your claim 


\title{
Chemistry
}

\section{A European}

Journal

\section{Chemistry Europe}

European Chemical Societies Publishing

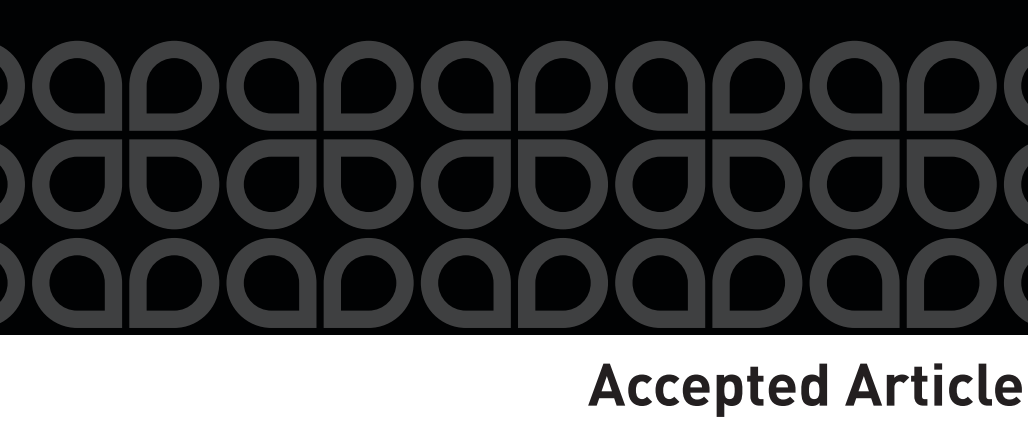

Title: Library Design Strategies to Accelerate Fragment-Based Drug Discovery

Authors: Nikolaj Sten Troelsen and Mads Hartvig Clausen

This manuscript has been accepted after peer review and appears as an Accepted Article online prior to editing, proofing, and formal publication of the final Version of Record (VoR). This work is currently citable by using the Digital Object Identifier (DOI) given below. The VoR will be published online in Early View as soon as possible and may be different to this Accepted Article as a result of editing. Readers should obtain the VoR from the journal website shown below when it is published to ensure accuracy of information. The authors are responsible for the content of this Accepted Article.
\end{abstract}

To be cited as: Chem. Eur. J. 10.1002/chem.202000584

Link to VoR: https://doi.org/10.1002/chem.202000584 


\section{MINIREVIEW}

\section{Library Design Strategies to Accelerate}

\section{Fragment-Based Drug Discovery}

Nikolaj S. Troelsen, ${ }^{\left[{ }^{[a]}\right.}$ and Mads H. Clausen ${ }^{*[a]}$

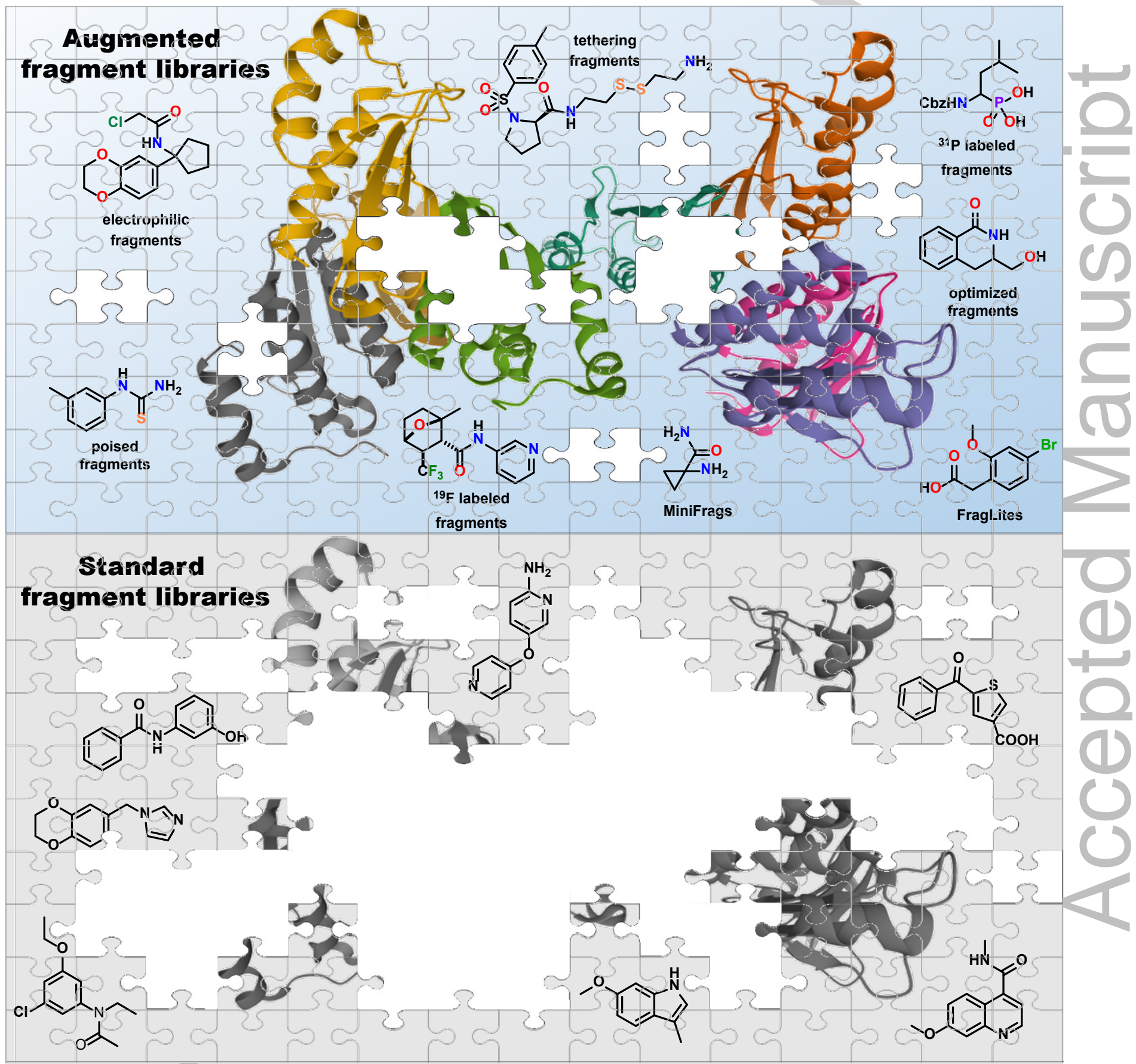




\section{MINIREVIEW}

[a] N. S. Troelsen and Prof. Dr. M. H. Clausen

Center for Nanomedicine and Theranostics, Department of Chemistry

Technical University of Denmark

Kemitorvet 207, 2800 Kongens Lyngby, Denmark

E-mail: mhc@kemi.dtu.dk

\begin{abstract}
Fragment-based drug discovery (FBDD) has become an established approach for the generation of early lead candidates. However, despite its success and inherent advantages, hit-tocandidate progression for FBDD is not necessarily faster than for the traditional high-throughput screening. Thus, new technology-driven library design strategies have emerged as a means to facilitate more efficient fragment screening and/or subsequent fragment-to-hit chemistry. This minireview will discuss such strategies, which cover the use of labelled fragments for NMR spectroscopy, X-ray crystallographic screening of specialized fragments, covalent linkage for mass spectrometry, dynamic combinatorial chemistry, and fragments optimized for easy elaboration.
\end{abstract}

\section{Introduction}

Fragment-based drug discovery (FBDD) has become a powerful approach in the discovery of new lead compounds. ${ }^{[1-7]}$ Screening of smaller fragments (Box 1) affords a series of advantages over the traditional high-throughput screening (HTS) including superior sampling of chemical space and higher hit rates. FBDD utilizes screening by sensitive biophysical techniques such as X-ray crystallography, NMR spectroscopy, and mass spectrometry (MS) in order to detect the often weaker binding of fragments. ${ }^{[2]}$

The success of FBDD critically depends on the library selected for screening and a number of excellent reviews have been written on this topic. ${ }^{[8-10]}$ Arguably, the most famous set of guidelines that the majority of fragments adhere to is the 'rule of three' (Ro3) proposed by researchers at Astex Pharmaceuticals nearly two decades ago (Box 1). ${ }^{[11,12]}$ Other important considerations include the removal of undesired functional groups (reactive, toxic, or ones prone to generate false positives) ${ }^{[13-15]}$ as well as achieving good library diversity to ensure better sampling of chemical space. While diversity is a rather subjective term, it is often associated with the inclusion of different pharmacophores and more recently especially focused on increasing shape diversity and 'three-dimensionality'. ${ }^{[16-20]}$ However, while diversity is generally important for targeting different classes of targets, focused libraries against specific targets have their inherent advantages. ${ }^{[10]}$

Despite the advances of $F B D D,{ }^{[2,5]}$ the approach is stil limited by laborious screening workflows and with hit-to-candidate progression that is not necessarily faster than for HTS. ${ }^{[2]}$ Consequently, much effort has been directed at optimizing screening technologies, fragment collections, and fragmentrelated chemistry. ${ }^{[2,8,21]}$ These advances have also affected how fragment libraries are designed and this field of technology-driven library design is reviewed herein.

The minireview will provide an overview of library design strategies used to accelerate FBDD by facilitating more efficient fragment screening and/or subsequent fragment-to-hit chemistry. Approaches described and discussed herein include labelled fragments for NMR-based screening, halogenated fragments for $\mathrm{X}$-ray crystallography, tethering approaches to assist mass spectrometry, dynamic combinatorial chemistry, and fragments optimized for easy hit elaboration. As such augmented fragment libraries can greatly enhance the output of early drug discovery, the minireview should in particularly be useful as inspiration for researchers looking to establish new fragment libraries or upgrade existing ones.

\section{Box 1}

While "fragment" is a somewhat subjective term it is generally accepted that fragments in drug discovery have molecular weights $<300 \mathrm{Da}$ as proposed by the renowned 'rule of three' (Ro3) guidelines. In addition, the Ro3 also proposes clogP $\leq$ 3 , number of hydrogen bond donors $\leq 3$, and hydrogen bond acceptors $\leq 3$ as useful metrics.

\section{Heteronuclear NMR Spectroscopy}

NMR spectroscopy was the first method to be successfully employed for fragment-based screening (SAR by NMR), ${ }^{[22]}$ and has since evolved into the most robust and sensitive technique for the detection of weak binders. ${ }^{[9]}$ Ligand-observed ${ }^{1} \mathrm{H}$ NMR methods are among the most widely applied methods and typically rely on the simultaneous screening of multiple fragments in cocktails. Unfortunately, because of the abundance of protons, overlap of signals from fragments, solvent, additives, and the target is a major hurdle. Thus, design of screening cocktails requires careful planning and are typically limited to only a handful of fragments at a time. ${ }^{[23]}$

Nikolaj Sten Troelsen, born in 1990, studied chemistry at the Technical University of Denmark (DTU) where he obtained his MSc degree in 2016. Since then, Nikolaj has pursued a PhD degree in fragment-based drug discovery focusing on library synthesis and compound screening under supervision of Professor Mads H. Clausen.

Mads Hartvig Clausen, born in 1974, studied chemistry at DTU where he obtained his PhD in 2002 with Professor Robert Madsen. Mads was a postdoctoral fellow at Harvard University from 2002-2004 with Professor Andrew Myers before returning to DTU as an assistant professor. In 2014, he became full professor of chemical biology at DTU. His research focuses on chemical biology, medicinal chemistry, and library synthesis. 
WILEY-VCH

\section{MINIREVIEW}

In contrast, heteronuclear detection schemes $\left({ }^{19} \mathrm{~F}\right.$ - or ${ }^{31} \mathrm{P}$ based screening) facilitate increased simplicity and sensitivity. The main advantage arises from the combination of wider chemical-shift dispersions, minimal background nuisance, and fewer reference signals (usually one) per screening compound. This greatly simplifies the analytical output (especially if proton decoupling is performed), increases sample throughput, and lowers protein consumption. ${ }^{[23]}$

\section{1. ${ }^{19} \mathrm{~F}$ NMR}

Fluorine is routinely used in drug discovery to improve physicochemical and metabolic properties and is found in approximately $20 \%$ of all marketed drugs. ${ }^{[24]}$ Desirable properties have also made the element particularly useful for NMR spectroscopy. ${ }^{19} \mathrm{~F}$ is $100 \%$ naturally abundant and exhibits a wide chemical-shift range spanning over several hundred ppm, which enables the routine screening of cocktails containing $\geq 30$ fragments. ${ }^{[23,25]}{ }^{19} \mathrm{~F}$ NMR screening is typically based on transverse $\left(T_{2}\right)$ relaxation-based experiments. These exploit the large difference in tumbling rates between large biomolecules and fragments along with a chemical exchange contribution arising from the difference in chemical shifts between free and bound states (Figure 1). The following section will highlight a few examples of fluorinated fragment libraries used for ${ }^{19} \mathrm{~F}$ NMR screening. For a more detailed analysis of the principles and application of ${ }^{19} \mathrm{~F}$ NMR screening in drug discovery, readers are referred to an extensive review recently published. ${ }^{[25]}$

Since the first reports of using ${ }^{19} \mathrm{~F}$ NMR spectroscopy for compound screening, ${ }^{[26,27]}$ the technique has increased in popularity in both industry and academia. In 2012, Amgen shared their experiences with the practical applications of ${ }^{19} \mathrm{~F}$ NMR screening: a library of 1200 fluorinated fragments was constructed from both commercial and in-house sources using various criteria including a diversity selection filter to achieve an approximate $30 \%$ coverage of available fragment space. ${ }^{[28]}{ }^{19} \mathrm{~F}$ NMR screening against 7 targets afforded hit rates between 0 and $8 \%$ and showed a good correlation to computationally predicted druggability of the targets. Interestingly, ${ }^{19} \mathrm{~F}$ NMR was also used for measuring $K_{d}$ values based on differential chemical shift perturbation. A later report described how screening of Amgen's ${ }^{19} \mathrm{~F}$ fragment library aided in the development of a potent and selective inhibitor against the Alzheimer's disease target BACE1. ${ }^{[29]}{ }^{19} \mathrm{~F}$ NMR-based screening was employed to identify a ligand for a second site and using a fragment linking approach this ultimately afforded a picomolar inhibitor with improved selectivity over the related aspartic protease cathepsin D.

Researchers at Novartis have developed a different strategy to ${ }^{19} \mathrm{~F}$ fragment library design by introducing a local fingerprint descriptor. ${ }^{[30,31]}$ Termed local environment of fluorine (LEF), this approach analyzes the chemical topologies surrounding the fluorine motif to construct a diverse library using fragments from both in-house and commercial collections, defragmentation of known ligands, and ad hoc synthesis. This approach also secured a large spread in ${ }^{19} \mathrm{~F}$ NMR chemical shifts. Interestingly, in the LEF library, fluorine was also regarded as an affinity tag to probe for "fluorophilic" protein environments and thus identifying fluorine-containing pharmacophores. This library has subsequently been employed in drug discovery campaigns against a range of targets including proteases and kinases. ${ }^{[32-34]}$

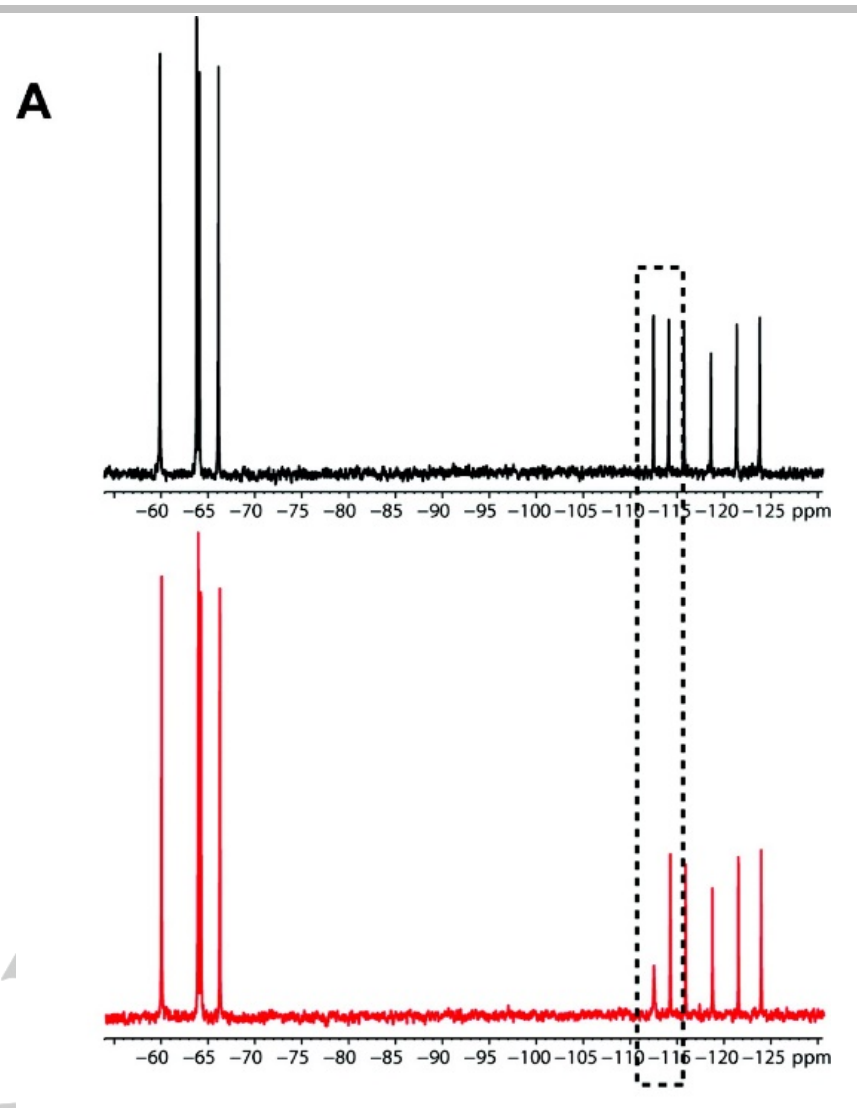

B

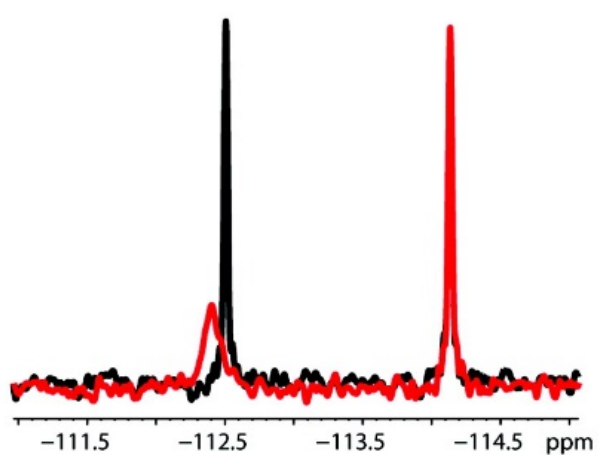

Figure 1. Example of fragment-based screening using ${ }^{19} \mathrm{~F}$ NMR spectroscopy. (A) Two spectra are recorded - one without protein as a reference (black) and one with protein (red). Fragment binding is observed as a significant reduction of ${ }^{19} \mathrm{~F}$ signal intensity upon addition of protein. This effect can typically be easily visualized using a $\mathrm{T}_{2}$-filter. (B) Expansion of box. Reprinted with permission from reference. ${ }^{[28]}$ Copyright (2012) American Chemical Society.

Recently, Clausen and co-workers published the synthesis and ${ }^{19} \mathrm{~F}$ NMR screening of their fluorinated $\mathrm{Fsp}^{3}$-rich fragment (3F) library - the first example of a synthetic library fully designed for this purpose (Figure 2). ${ }^{[35]}$ With a high degree of 'threedimensionality', the 3F library was designed to address the need of improving the limited shape diversity of many fragment collections while enabling efficient screening by ${ }^{19} \mathrm{~F}$ NMR. Furthermore, the library also exhibited other desirable properties compared to commercial collections including a low average ALogP of 0.8 to ensure sufficient aqueous solubility. As a proofof-concept, the $3 \mathrm{~F}$ library was screened against four diseaserelated targets to provide a total of 30 hits (hit rates ranging from 3 to $11 \%$ ). Subsequent validation primarily by ${ }^{1} \mathrm{H}$ NMR-based assays validated $2 / 3$ of the initial ${ }^{19} \mathrm{~F}$ NMR hits. 
WILEY-VCH

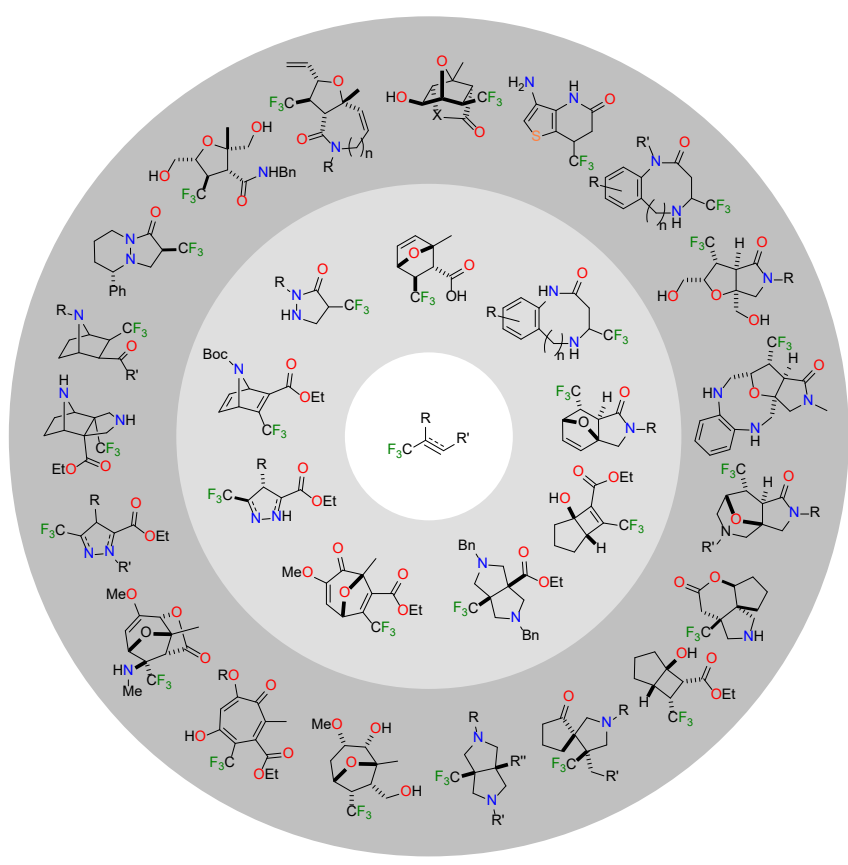

Figure 2. Synthesis of the fluorinated Fsp $\mathrm{F}^{3}$-rich fragment (3F) library. Starting from a handful of similar and readily available $\mathrm{CF}_{3}$-containing starting materials (white center), a collection of nine core scaffolds was initially synthesized (light grey middle) followed by further structural modifications to afford 115 diverse fluorinated fragments (outer dark grey, representative structures). Adapted with permission from reference. ${ }^{[35]}$ Copyright (2020) John Wiley and Sons.

The application of heteronuclear NMR spectroscopy enables the use of hits as spy molecules in a subsequent reporter assay where non-labelled molecules can be screened for displacement of the spy molecule (Figure 3 ). ${ }^{[25,36]}$ As it may be challenging to access large libraries of labelled fragments, this approach allows initial screening of a smaller library of labelled compounds in search of a suitable spy molecule. The following reporter assay will only identify specific binders as determined by displacement of the spy molecule.

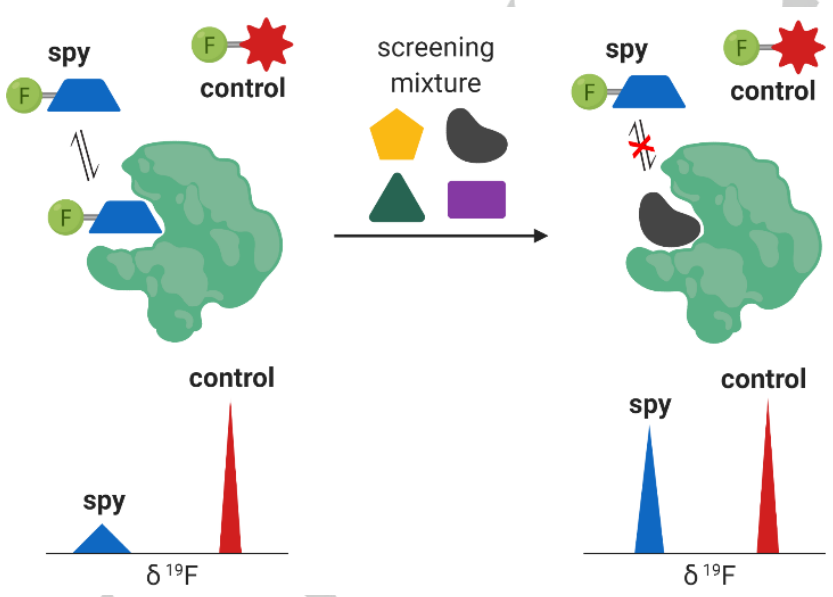

Figure 3. Schematic Illustration of a displacement assay with ${ }^{19} \mathrm{~F}$ NMR spectroscopy. Mixtures of non-fluorinated compounds can be screened against a known fluorinated ligand - the spy molecule (blue). The broad signal of the spy molecule (indicating binding) becomes sharper upon displacement by another binder (black). Deconvolution of the screening mixture is then performed to identify the structure of the new binder. A control molecule (red) is often included as an internal reference.
While fluorine in the context of screening functions as a reporter tag, it is worth noting its value as a bioisostere in modern drug discovery. ${ }^{[24,37]}$ Thus, removal of fluorine during fragment elaboration is not necessary if the element participates in fruitful interactions and/or improves ADME properties of the lead compounds. Unfortunately, ${ }^{19} \mathrm{~F}$ NMR screening provides only little binding information and the technique must be complimented by other methods such as X-ray crystallography in order to obtain important structural information. Another disadvantage of this approach lies with the need for using fluorinated fragments. However, once such a fluorinated library has been constructed, rapid screening by ${ }^{19} \mathrm{~F}$ NMR is a routine matter and can be applied to a wide range of targets. ${ }^{[25]}$

\section{2. ${ }^{31 P}$ NMR}

Phosphorus $\left({ }^{31} \mathrm{P}\right)$ is the only other heteronucleus besides fluorine that has been employed for ligand-observed NMR screening. In 2008, Kessler and co-workers published the use of ${ }^{31} \mathrm{P}$ NMR as a useful tool for compound screening. ${ }^{[38]}$ Like ${ }^{19} \mathrm{~F},{ }^{31} \mathrm{P}$ is $100 \%$ naturally abundant and exhibits a wide chemical-shift dispersion. While phosphorus is arguable less interesting in the context of medicinal chemistry, the element is still found in numerous natural products and approved drugs. ${ }^{[38]}$ Phosphorus-containing groups can also be used to mimic the tetrahedral intermediate of peptide bond hydrolysis (transition state analogues) and ${ }^{31} \mathrm{P}$ NMR is therefore well suited for screening against proteases.

As a proof-of-concept, the authors demonstrated the use of ${ }^{31} \mathrm{P}$ NMR against the protease thermolysin. Five phosphorus containing fragments were screened against the protease, and they were able to show binding of one fragment. Specific binding was confirmed by displacement of the hit with a known inhibitor (Figure 4).

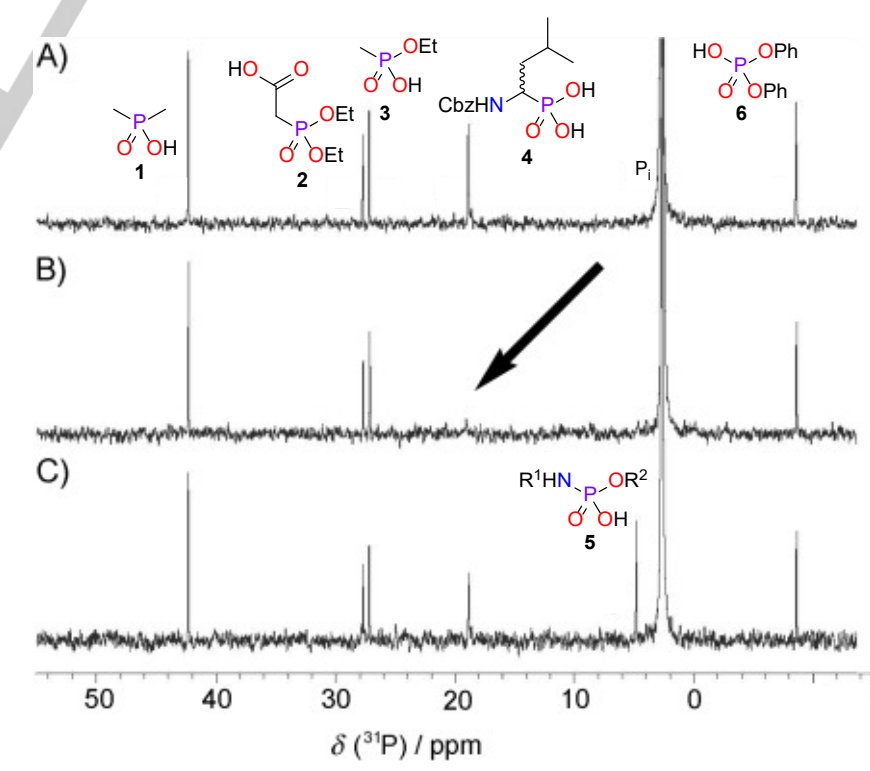

Figure 4. ${ }^{31} \mathrm{P}$ NMR screening against thermolysin with phosphorous containing fragments (each $0.5 \mathrm{mM}$ ). (A) Without thermolysin. (B) With thermolysin $(0.25 \mathrm{mM})$. C) Recovery of the signal for 4 by displacement with the tightly binding phosporamidon $5(0.5 \mathrm{mM}) . \mathrm{R}^{1}=$ L-leucyl-L-tryptophan. $\mathbf{R}^{2}$ $=\alpha$-L-rhamnopyranosyl. $\mathrm{P}_{\mathrm{i}}=$ phosphate buffer signal. Adapted with permission from reference. ${ }^{[38]}$ Copyright (2008) John Wiley and Sons. 
WILEY-VCH

\section{MINIREVIEW}

\section{X-ray Crystallography}

The routine application of X-ray crystallographic screening was pioneered at both Abbott Laboratories ${ }^{[39]}$ and Astex Pharmaceuticals ${ }^{[40]}$ and is probably the most powerful tool for fragment-based screening. The approach provides both hit validation and structural binding information, which is essential for structure-guided drug design. ${ }^{[10]}$ While screening by X-ray crystallography has historically been considered impractical due to low throughput; modern, automated setups and the screening of fragment mixtures have significantly increased efficiency. ${ }^{[41]}$

Fragments generally bind weakly and thus only achieve partial occupancy in proteins. Consequently, this may result in difficultto-fit electron density maps and can make it challenging to detect binding. ${ }^{[42,43]}$ This can be tackled by performing crystal soaking at high fragment concentrations to facilitate high protein occupancy. An efficient screening methodology along those lines termed MiniFrags was recently reported by researchers at Astex Pharmaceuticals. ${ }^{[44]}$ Using highly soluble and ultra-low molecular weight fragments (heavy atom count 5-7), fragments could be used at $1 \mathrm{M}$ concentrations, which enabled more efficient $\mathrm{X}$-ray crystallographic screening with an impressive average hit rate of $44 \%$ (Table 1). Some representative structures from the MiniFrag library are depicted in Figure 5.

Table 1. Summary of average properties of the Astex MiniFrag collection and historical X-ray screening sets. The smaller and more polar MiniFrags enabled soaking at $1 \mathrm{M}$ and $\mathrm{X}$-ray crystallographic screening resulted in significantly higher hit rates compared to their previous X-ray set. ${ }^{[44]}$

\begin{tabular}{cccccccc} 
& $\mathrm{N}$ & $\begin{array}{c}\mathrm{MW} \\
(\mathrm{Da})\end{array}$ & $\operatorname{clogP}$ & $\mathrm{Fsp}^{3}$ & $\mathrm{HBA}$ & $\mathrm{HBD}$ & $\begin{array}{c}\text { Hit rate } \\
(\%)\end{array}$ \\
\hline MiniFrags & 81 & 94 & -0.4 & 0.5 & 1.5 & 1.9 & 44 \\
$\begin{array}{l}\text { Historical } \\
\text { X-ray set }\end{array}$ & 440 & 150 & 0.6 & 0.3 & 2.0 & 1.7 & 12 \\
\hline
\end{tabular}

$\mathrm{N}=$ number of fragments; $\mathrm{MW}=$ molecular weight; $\operatorname{clog} \mathrm{P}=$ calculated partition coefficient; $F \mathrm{sp}^{3}=$ fraction of $\mathrm{sp}^{3}$-hybridized carbon atoms; $\mathrm{HBA}=$ hydrogen bond acceptor; HBD = hydrogen bond donor.

Alternatively, the introduction of heavy atoms can address this challenge as they can be unequivocally located by anomalous scattering. ${ }^{[45]}$ Thus, the use of halogenated (primarily brominated) fragments may significantly enhance screening by X-ray crystallography. Halogens may also participate in binding interactions via halogen bonds and are as such not necessarily only a reporter tag. ${ }^{[46,47]}$ Furthermore, even if a halogen is not directly involved in binding, it may enable easy synthetic elaboration via various coupling reactions. ${ }^{[48-50]}$

SGX Pharmaceuticals (now part of Eli Lilly) was among the first to report the inclusion of brominated fragments to improve both screening by $\mathrm{X}$-ray crystallography and subsequent hit-tolead chemistry. ${ }^{[51]}$ Out of their 1000-membered library, at least $50 \%$ of the fragments were brominated. The advantage of halogenated fragments also became apparent to Arnold and coworkers during a crystallographic screen against HIV-1 reverse transcriptase: an impressive hit rate of almost $25 \%$ was observed for subsets of both brominated and fluorinated fragments compared to an overall hit rate of $4 \%$ for the 742 fragments screened. ${ }^{[52]}$

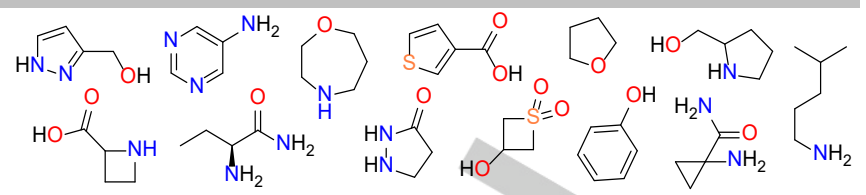

Figure 5. Selection of representative structures included in the MiniFrag X-ray set from Astex Pharmaceuticals. ${ }^{[44]}$

Inspired by these results, Tiefenbrunn and co-workers reported the first fully brominated library of 68 fragments in 2014. ${ }^{[42]}$ Screening against an HIV-1 protease, they reported a hit rate roughly four times higher than previously reported screens against this target ( $3 \%$ vs. $0.8 \%)$. Furthermore, the approach provided additional structural information about the protein by mapping different binding sites and led to the discovery of novel hits.

A particularly elegant approach to assessing target druggability using minimal, halogenated fragments (FragLites) was reported by Waring and co-workers in 2019. ${ }^{[43]}$ The FragLites library was constructed from 31 small (heavy atom count < 14) brominated or iodinated fragments that each contained a pharmacophore doublet to efficiently probe for polar proteinligand interactions (Figure 6).

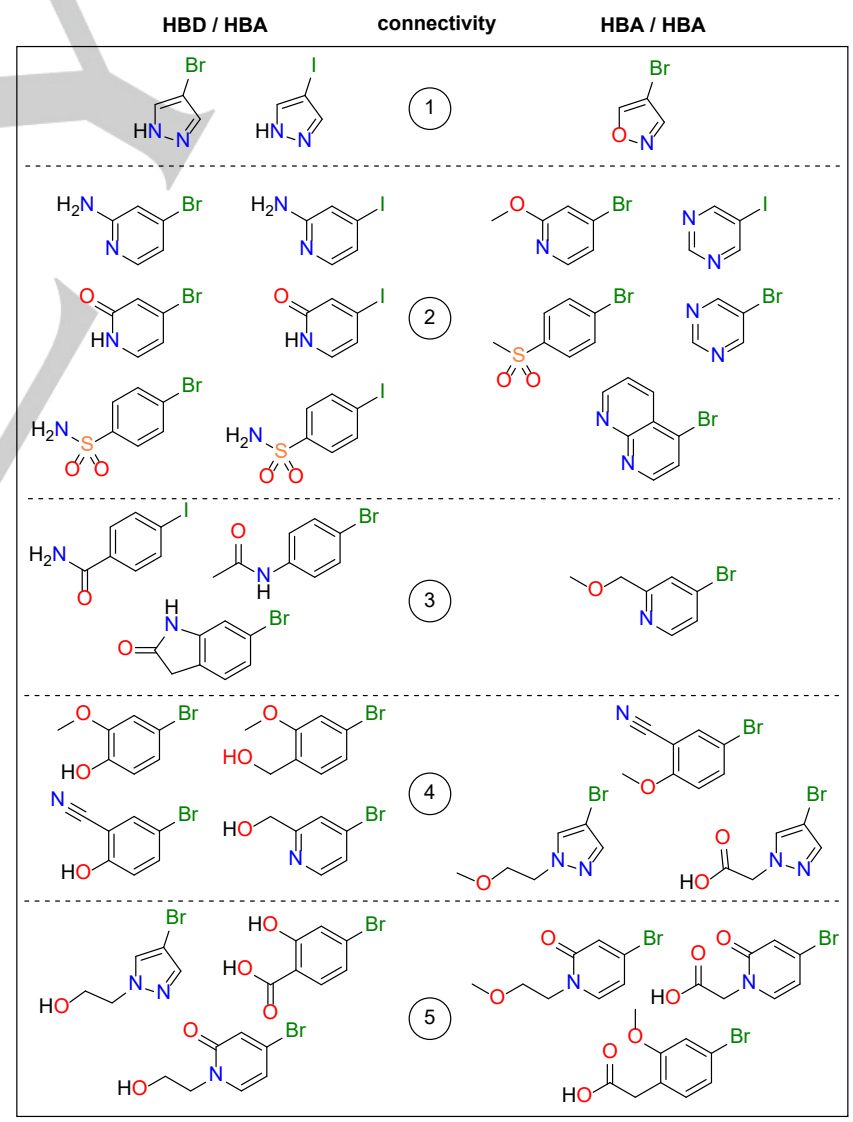

Figure 6. An overview of the 31 small and halogenated FragLites. Each fragment contains a pharmacophore doublet consisting of either a hydrogen bond donor-acceptor (HBD/HBA) pair (left) or an HBA/HBA pair (right). Pharmacophore doublets were spaced apart by one to five bonds (connectivity). ${ }^{[43]}$ 
WILEY-VCH

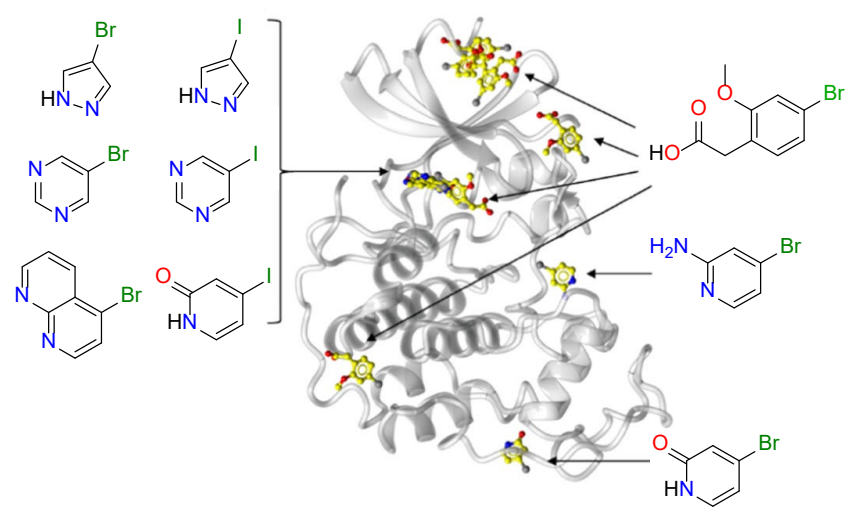

Figure 7. X-ray crystallographic screening results of the FragLites library against CDK2. Adapted with permission from reference. ${ }^{[43]}$ Copyright (2019) American Chemical Society.

The pharmacophore doublets consisted of combinations of hydrogen bond donor-acceptor or acceptor-acceptor pairs spaced apart by one to five bonds. As a proof-of-concept, binding site mapping of the well described kinase CDK2 was performed and successfully identified both ortho- and allosteric sites with an impressive hit rate of $29 \%$ (Figure 7). The utility of the method was further demonstrated by fragment hit elaboration (merging or growing) into more potent ligands.

While the use of halogenated fragments seems to substantially increase hit rates by facilitating better crystallographic data, halogens may not only be innocent bystanders. Halogen bonding is a well-known phenomenon and may be desirable in some cases. However, the large and lipophilic nature of bromine and iodine may also simply increase promiscuity through non-specific interactions to the many hydrophobic sites in proteins. Thus, some caution should be taken when assessing the different hits obtained. In the event that the halogens are participating in fruitful interactions, this may also complicate hit-to-lead optimization as bromine and iodine are reactive towards many of the typical reactions used in medicinal chemistry.

Finally, the application of minimal pharmacophore fragments may also present another challenge for fragment elaboration. As fragments become simpler, hit rates are bound to increase and promiscuity can be a concern, although selectivity is often achieved later, during fragment elaboration. However, the use of simple fragments may prevent the identification of novel and unique binding motifs that could otherwise have been identified by screening of more conventional fragments something that is also worth considering in regards to intellectual property.

\section{Covalent Linking for Mass Spectrometry}

Mass spectrometry (MS) is a less established but nonetheless appealing screening technique for FBDD. ${ }^{[53,54]}$ Native electrospray ionization (ESI) MS allows for the detection of noncovalent target-ligand complexes and provides direct deconvolution of screening mixtures (assuming unique molecular weights of fragments), information on binding stoichiometry, and relative binding affinities. Compared to screening by NMR spectroscopy and X-ray crystallography, MS offers greater sample throughput and lower protein consumption. Unfortunately, achieving detectable target occupancy and ensuring survival of the target-ligand complexes in the gas-phase can be challenging, particularly for weak binders. Consequently, MS is generally better suited for detection of covalent inhibitors. ${ }^{[10,55]}$

\subsection{Reversible Tethering}

Sunesis Pharmaceuticals has developed an interesting approach termed tethering, in which a natural or engineered reactive functionality in a protein is used to capture fragments binding in the vicinity. ${ }^{[56]}$ In addition to facilitating screening by MS, the method also controls the region where fragments can bind. In most cases, a cysteine residue within or adjacent to the active site is exploited to reversibly bind disulfide-containing fragments via a new disulfide bridge (Figure 8$){ }^{[55]}$ Assuming equivalent reactivity of selected disulfides, the approach enables screening of mixtures. Intact-protein MS can then be used to detect if any protein-fragment complexes are prevalent. As such, tethering is related to dynamic combinatorial chemistry (DCC). ${ }^{[57]}$

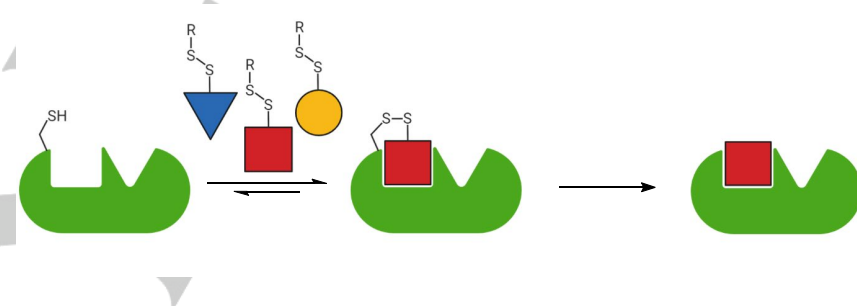

Figure 8. Schematic illustration of tethering approaches. A cysteinecontaining protein (natural or engineered) is screened against a library of disulfide-containing fragments. In the event of binding, the equilibrium is shifted towards the modified protein, which can be detected using MS. In contrast to covalent inhibitors, the disulfide linkage is only used as a means to identifying hits and is removed for subsequent hit elaboration.[56]

Fragments designed for disulfide tethering must naturally include a thiol group (typically masked as a disulfide). As the commercial availability of such disulfide-containing fragments is rather limited, the approach often involves synthesis of an appropriate library. ${ }^{[58,59]}$ To increase aqueous solubility, disulfidecontaining fragments can advantageously contain a solubilizing group (e.g. an amine) attached on one side of the disulfide and a variable group on the other. To ensure similar reduction potentials of the disulfide moieties, a short spacer should be included to separate the disulfide from the rest of the fragment (Figure 9).

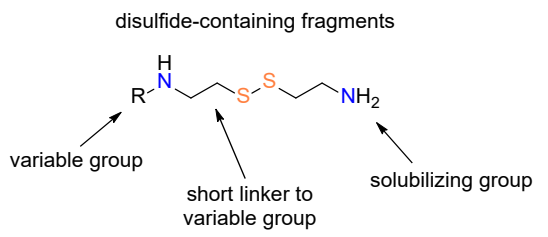

Figure 9. Generic disulfide fragment for tethering approaches.

In the first reported example of tethering, the prominent cancer target thymidylate synthase, which relies on a catalytic 
WILEY-VCH

\section{MINIREVIEW}

cysteine in the active site, was selected. ${ }^{[56]}$ A bespoke library of 1200 disulfide-containing fragments was screened in mixtures of 8-15 compounds using intact-protein MS and afforded a promising $N$-tosyl-D-proline hit (7) with low millimolar potency (Scheme 1). Importantly, similar binding modes between the tethered and noncovalent hit were demonstrated using X-ray crystallography. Subsequent merging of the hit with the natural cofactor methylenetetrahydrofolate followed by fragment growing afforded the nanomolar inhibitor 9 .

Tethering has since been successfully employed in the discovery of numerous new ligands including kinase inhibitors, ${ }^{[60]}$ disrupters of protein-protein interactions ${ }^{[61]}$ and allosteric binders. ${ }^{[62,63]}$ An interesting continuation of this approach is extended tethering, which transforms the technology from fragment discovery to fragment assembly. ${ }^{[64]}$ Incorporation of a thiol extender into a known binder enables screening against disulfide-containing fragments and provides an opportunity to identify adjacently binding fragments (Figure 10).

\subsection{Irreversible Covalent Inhibitors}

One of the main advantages of using tethering is that the approach is applicable to many proteins, assuming a cysteine residue can be introduced by site-directed mutagenesis. Once hits are identified, the disulfide linker is removed and medicinal chemistry is continued on the native protein. However, if a cysteine-containing protein is targeted, searching for an irreversible covalent inhibitor is also an option. Covalent inhibitors offer several pharmacological advantages including improved potency and prolonged duration of action. ${ }^{65,66]}$ However, minimizing off-target reactivity is a challenge. Historically, covalent inhibitors have been developed by incorporation of an electrophilic moiety into an already optimized reversible inhibitor (Figure 11). ${ }^{[67-69]}$

However, recent reports have shown that screening of electrophilic fragments may serve as an efficient tool for covalentligand discovery. ${ }^{[70]}$ Similar to reversible tethering, screening of electrophilic fragments can advantageously be performed with mixtures and analyzed by intact-protein MS. ${ }^{[71,72]}$ To ensure that hits represent the best binding fragments rather than the most

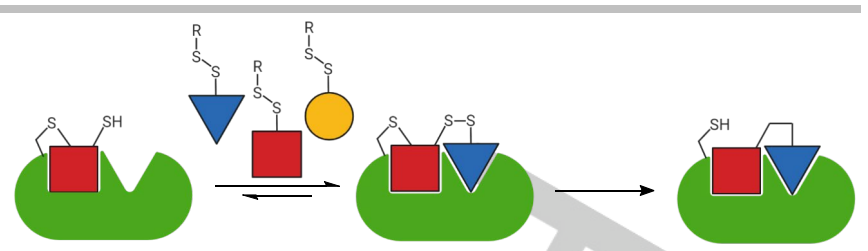

Figure 10. Extended tethering can be used to identify new fragment binders within a binding site. Introduction of an extender (thiol, potentially masked) to a known ligand enables screening against a disulfide-containing library. If a new binder is identified in an adjacent site, the temporary disulfide bridge can be replaced with an alternative linker to form a more potent binder. ${ }^{[64]}$

reactive ones, cocktails should be comprised of fragments with comparable electrophilicity. A number of electrophilic warheads can be implemented for this approach and an interesting study of the promiscuity and selectivity of such electrophiles has been published by Klein and co-workers. ${ }^{[73]}$ For cysteine-containing targets, chloroacetamides and Michael acceptors are predominantly used.

An impressive example of covalent fragment screening was recently published by London and co-workers, who reported screening of a mildly electrophilic fragment library. ${ }^{[69]}$ The collection consisted of 993 commercially available and generally 'Ro3'-compliant fragments containing either a chloroacetamide or an acrylamide warhead. The reactivities of the electrophilic fragments were assessed in a high-throughput thiol-reactivity assay, which confirmed that the electrophiles had suitable reactivity and a limited variation in intrinsic reactivity. Relying on intact-protein MS, the library was screened against 10 different cysteine-containing protein targets identifying hits against seven of them (Figure 12). Interestingly, only relatively low promiscuity of the electrophilic fragments was observed against the 10 targets and the promiscuity observed was not correlated with the intrinsic reactivity of the fragments. For two targets-deubiquitinase OTUB2 and pyrophosphatase NUDT7-the method was combined with X-ray crystallography and led to the development of potent and selective novel probes.
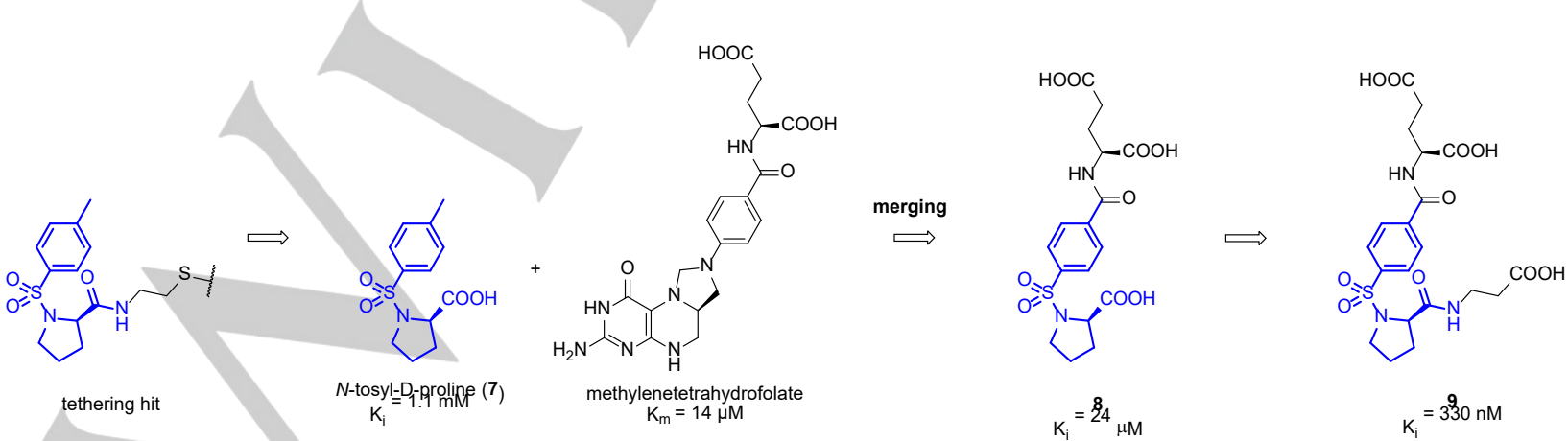

Scheme 1. Hit-to-lead elaboration of $\mathrm{N}$-tosyl-D-proline (7) into the nanomolar inhibitor 9 of thymidylate synthase via merging with methylenetetrahydrofolate. [56] 
WILEY-VCH

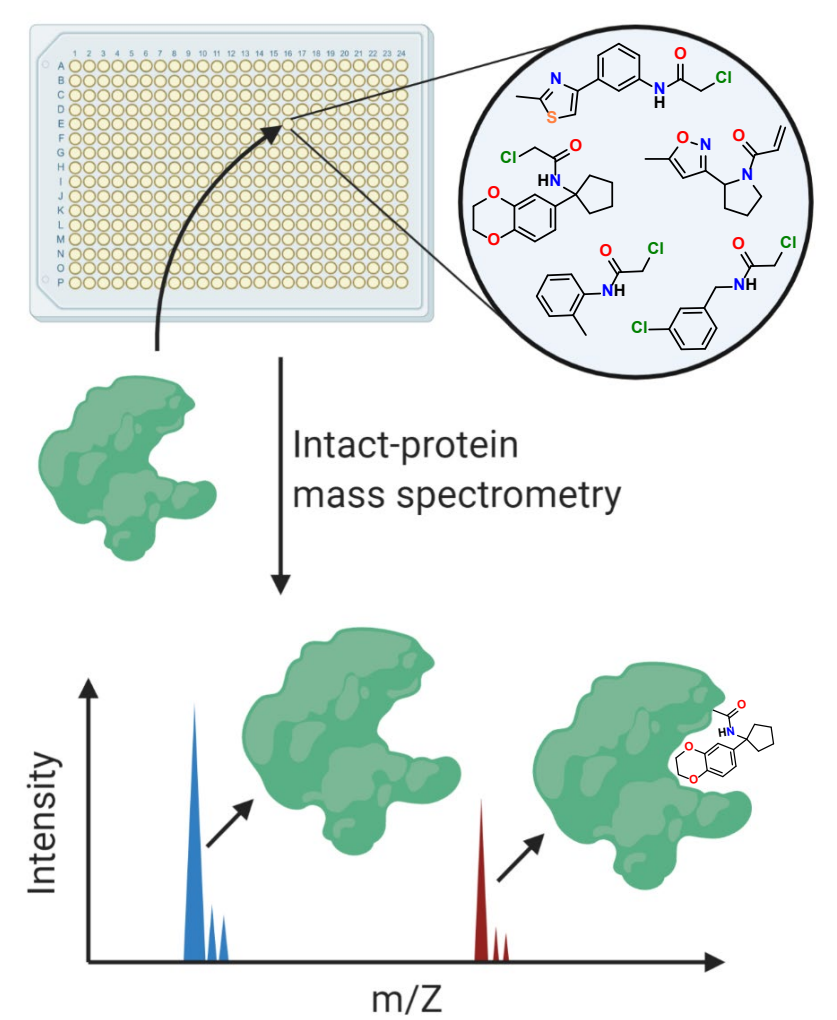

target-directed DCC (tdDCC) offers an attractive approach for simultaneous hit identification and fragment linking and has been extensively applied for fragment-based screening. ${ }^{[77]}$ The most useful reversible reactions for tdDCC include imine formation, acylhydrazone formation, thiol-disulfide exchange, boronate trans-esterification, and hemithioacetal formation.

Screening by tdDCC may be performed in one of two ways: comparative or non-comparative. In the former, hit identification is based on an amplification of high affinity ligands in the presence of the target compared to a 'blank library' without target. In contrast, the non-comparative approach relies on detection of binding without comparison to a control library. This is typically performed by either analysis of target-ligand complexes using methods like intact-protein MS or NMR spectroscopy or detection of ligands after disruption of isolated target-ligand complexes. ${ }^{[77]}$

A comparative tdDCC approach targeting the aspartic protease endothiapepsin was reported by Hirsch and coworkers. ${ }^{[78]}$ Relying on the reversible formation of mono- and bisacylhydrazones from bis-aldehyde $\mathbf{1 0}$ and nine hydrazides, the authors compared library equilibria in the absence and presence of the target using HPLC. A two-to-three fold amplification of six bis-acylhydrazones were observed with homodimer 11 being the most potent hit with a $\mathrm{K}_{\mathrm{i}}$ of $25 \mathrm{nM}$ (Scheme 2).

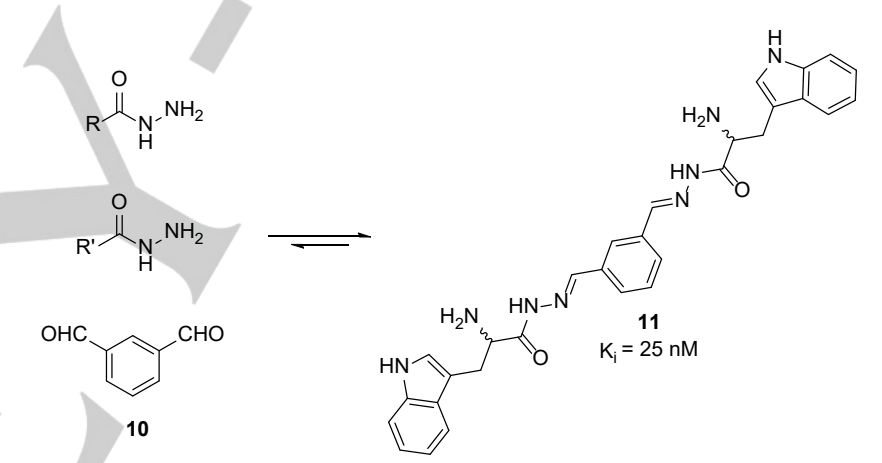

\section{Target-Directed Dynamic Combinatorial Chemistry}

Dynamic combinatorial chemistry (DCC) relies on reversible covalent reactions to form complex dynamic libraries under thermodynamic control. ${ }^{[7]}$ As such chemical systems are responsive to external stimuli, where for example the addition of a macromolecular template (e.g. a protein) may shift the equilibrium by non-covalent stabilization and thus lead to the amplification of selected library members (Figure 13). ${ }^{[75,76]}$ This

Scheme 2. Fragment-based tdDCC used to identify potent binders of the aspartic protease endothiapepsin. Screening of bis-aldehyde 10 in combination with nine hydrazides led to amplification of six bis-acylhydrazones (comparative analysis by HPLC) including the potent ligand 11, whose binding mode was determined by X-ray crystallography. ${ }^{[78]}$
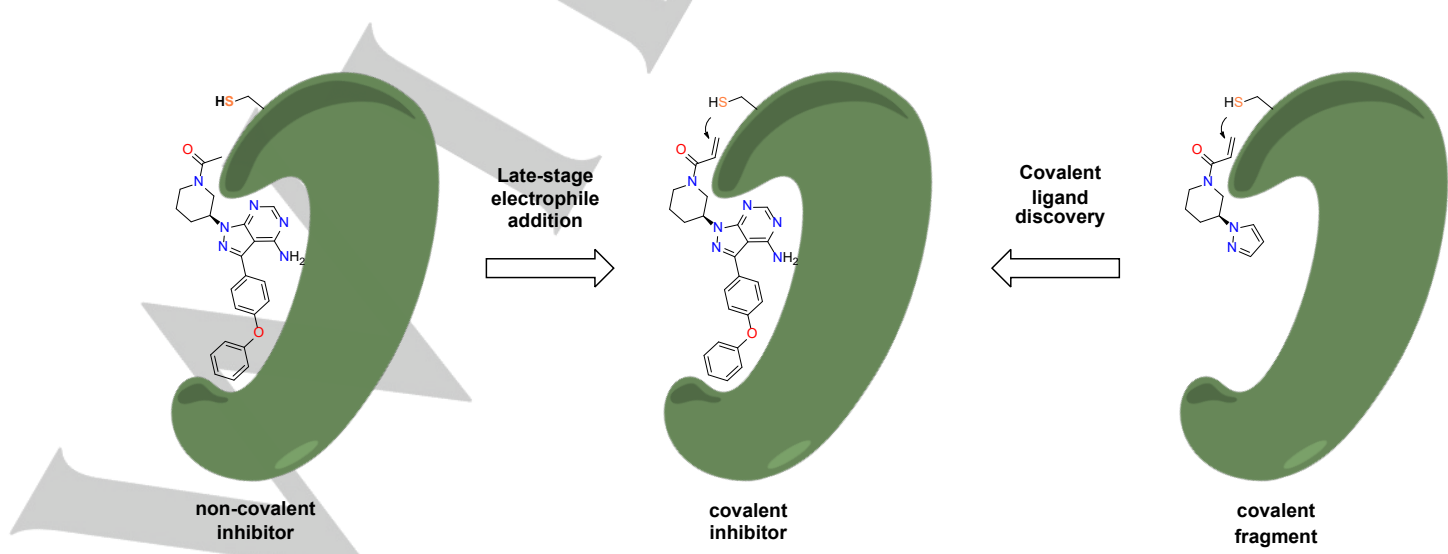

Figure 12. Representation of complementary strategies for developing covalent inhibitors. Development of covalent inhibitors has traditionally been based on a late-stage incorporation of an electrophilic moiety using structure-guided design (left). In contrast, fragment-based methods using electrophilic fragments may offer a new approach to finding selective covalent inhibitors (right). 


\section{MINIREVIEW}

Schofield and co-workers demonstrated a non-comparative approach against 2-oxoglutarate-dependent nucleic acid demethylase, an enzyme involved in nucleic acid repair and modification. ${ }^{[79]}$ tdDCC via disulfide formation was performed with the known ligand $\mathrm{N}$-oxalyl-L-cysteine (12) and a small library of thiols and resulted in identification of three disulfide hits (Scheme 3). After transformation into more stable carbon analogues, hit 14 showed most promise and binding was confirmed by crystallographic analysis.

While tdDCC is conceptually very appealing, the approach still suffers from limitations. For comparative methods, it can be a significant challenge to separate library members from the protein prior to analysis without altering the established equilibrium. ${ }^{[80]}$ Furthermore, equimolar amounts of fragments and protein (high protein consumption) are often needed to produce an effect and even then only minor differences in the equilibria are observed (e.g. the modest three-fold amplification for the $25 \mathrm{nM}$ binder 11).

For non-comparative methods, it may be difficult to distinguish whether ligands are truly amplified as no comparison to a blank sample is performed. Thus, most tdDCC studies remain at a proof-of-concept level relying on either well-characterized proteins or the use of only small and often biased dynamic libraries.

$$
{ }_{12}^{\mathrm{HOOC}} \underbrace{\mathrm{COOH}}_{\mathrm{SH}}
$$

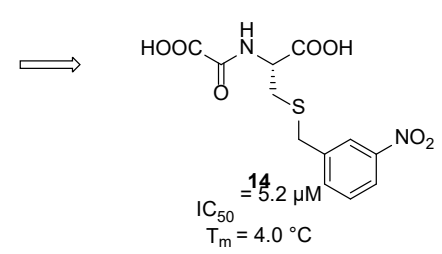

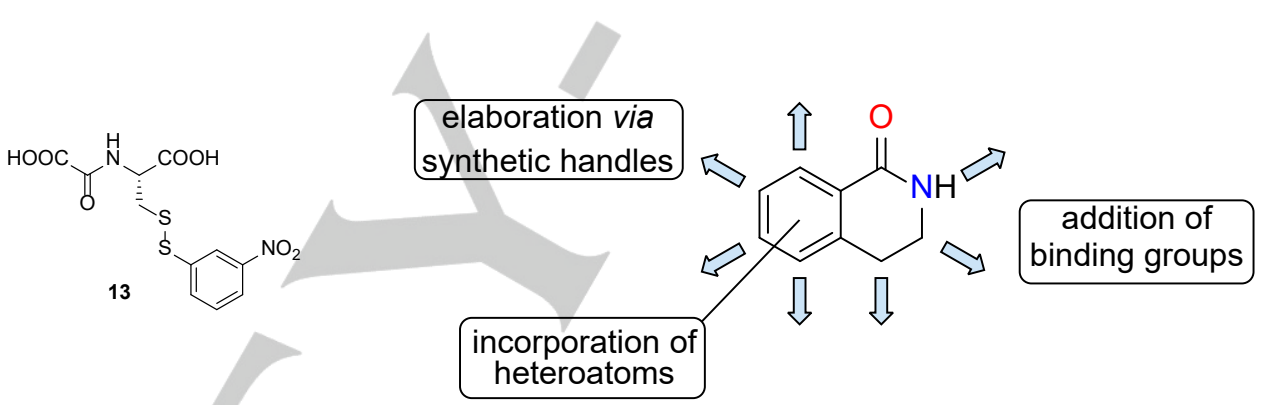

Figure 13. Example of a fragment optimized for easy hit elaboration with many available growth position (blue arrows) and the possibility of including heteroatoms in the aromatic moiety. ${ }^{[82]}$

Scheme 3. Non-comparative tdDCC approach using intact-protein MS against 2-oxoglutarate-dependent nucleic acid demethylase. Screening a small library of 37 thiols in the presence of $N$-oxalyl-L-cysteine (12) led to the identification of

three hits including 13. Linker exchange into a more stable thioether afforded 14 as the most promising compound, which was further validated by X-ray crystallography. ${ }^{[79]}$

\section{Fragments Optimized for Rapid Hit-to-Lead Chemistry}

Fragment-to-lead optimization is a frequently encountered bottleneck in FBDD. ${ }^{[81]}$ This can be a particularly time-consuming endeavor if the elaboration chemistry has not been properly developed or the fragment hit is poorly optimizable with few handles available. Indeed, having fragments optimized for rapid hit-to-lead chemistry has been stressed by researchers at Astex Pharmaceuticals, who recommend establishing the elaboration chemistry prior to screening. ${ }^{[21]}$ As an example of this methodology, they published the synthesis of a simple dihydroisoquinolone fragment that can easily be elaborated using a variety of available growth vectors (Figure 14). ${ }^{[82]}$

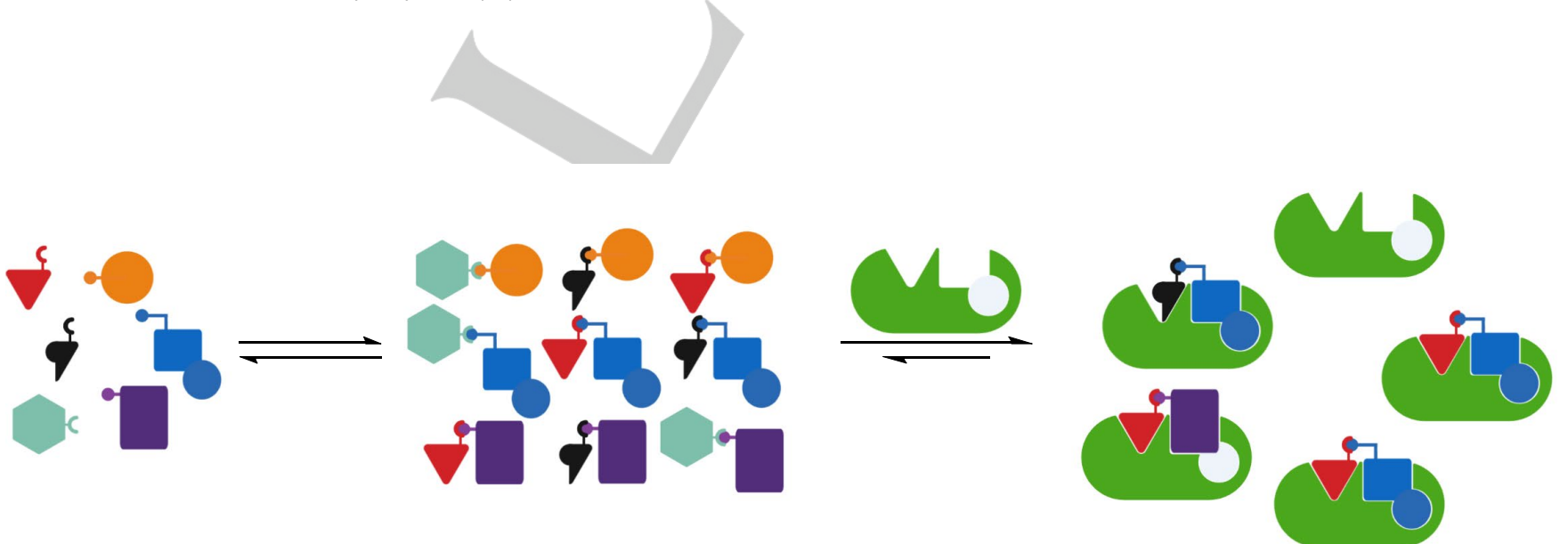

Figure 14. Schematic illustration of target directed dynamic combinatorial chemistry (tdDCC). A library of complementary reactive building blocks undergoes reversible covalent reactions to form a dynamic library. External stimulus by a target (template) shifts the equilibrium towards high-affinity ligands. 
WILEY-VCH

\section{MINIREVIEW}

This particular challenge was addressed by Brennan and co-workers who developed a poised fragment library for rapid hit elaboration. ${ }^{[83]}$ Poised fragments were designed such that they could easily be deconstructed into at least two synthons. Using one-step chemistry, each synthon could be paired with other synthons to quickly access fragment analogues for screening (Figure 15). A simple example of this includes amides, which can easily be deconstructed into an amine and a carboxylic acid.

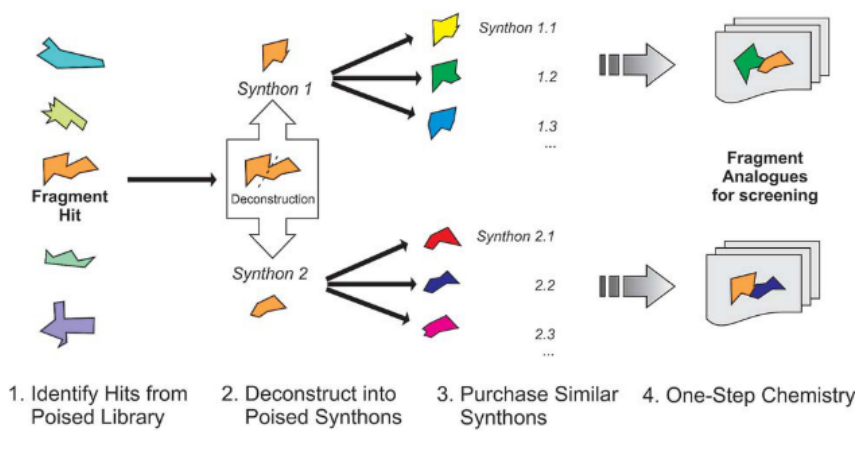

Figure 15. Schematic illustration of hit elaboration from a poised fragment hit. Hits are deconstructed into synthons and paired with similar and commercially available synthons using one-step chemistry to enable rapid follow-up screening Reproduced from reference ${ }^{[83]}$ with permission from The Royal Society of Chemistry.

To enable rapid elaboration by parallel chemistry, the poised fragments were synthesized using simple and robust chemistry. Core structures were therefore based on the ten most reliable and commonly encountered reactions in medicinal chemistry along with 12 well-defined heterocycle-forming reactions (Figure 16). To demonstrate the utility of the approach, their first generation poised library of 406 in-house fragments was screened against the challenging and atypical bromodomain PHIP(2) using X-ray crystallography. Four hits were identified and subsequently optimized into the first micromolar inhibitors of this target. Based on this initial success, a second generation poised library of 1000 fragments was constructed from commercially available fragments to ensure a broader applicability of the approach.

\section{Other Approaches}

As briefly mentioned in the introduction of this minireview, the use of focused fragment libraries may offer improved hit rates when screening against specific targets (rather than against a range of diverse target classes). ${ }^{[10]}$ This strategy has in particularly been successful against kinases relying on prior knowledge of relevant pharmacophores ${ }^{[84]}$ An interesting strategy in this context is the deconstruction-reconstruction approach where known ligands are deconstructed into biased fragments. ${ }^{[85,86]}$ After screening, the most promising fragments can then be reconstructed into more potent inhibitors via fragment linking, merging, or growing (often the most challenging process of this approach).

Along the same lines of breaking down bioactive molecules to access privileged fragments, the synthesis of natural product- like fragments has also attracted attention in FBDD. ${ }^{[87]}$ Natural products are from evolution predisposed to biological activity and have served as a major source of inspiration for drug discovery. ${ }^{[88,89]}$ As such, it is worth considering to include natural product-like structures in fragment collections to enhancing the biological relevance of a screening library.

\section{Summary and Outlook}

The utility of augmented fragment libraries may greatly enhance early FBDD. Technological advances have enabled a range of fragment library design strategies. Depending on the circumstances (e.g. target biomolecule, in-house screening capabilities), specific strategies may prove more promising than others. While X-ray crystallography is often considered the golden standard for screening, the method requires a protein that crystallizes well and access to synchrotron beam time. Thus, NMR spectroscopy may be easier to implement for routine screening or when targeting disordered proteins. If native cysteine residues are present or easily incorporated near a binding site of interest, then a tethering and mass spectroscopy approach could prove advantageous. Limited in-house chemistry resources can also affect the library design process and for instance lead to a priority on fragments that are more easily optimized instead. It is worth noting that different screening techniques often produce different hits from the same library and as such it is generally recommended to rely on complementary screening methods for FBDD campaigns. ${ }^{[8,10,90]}$

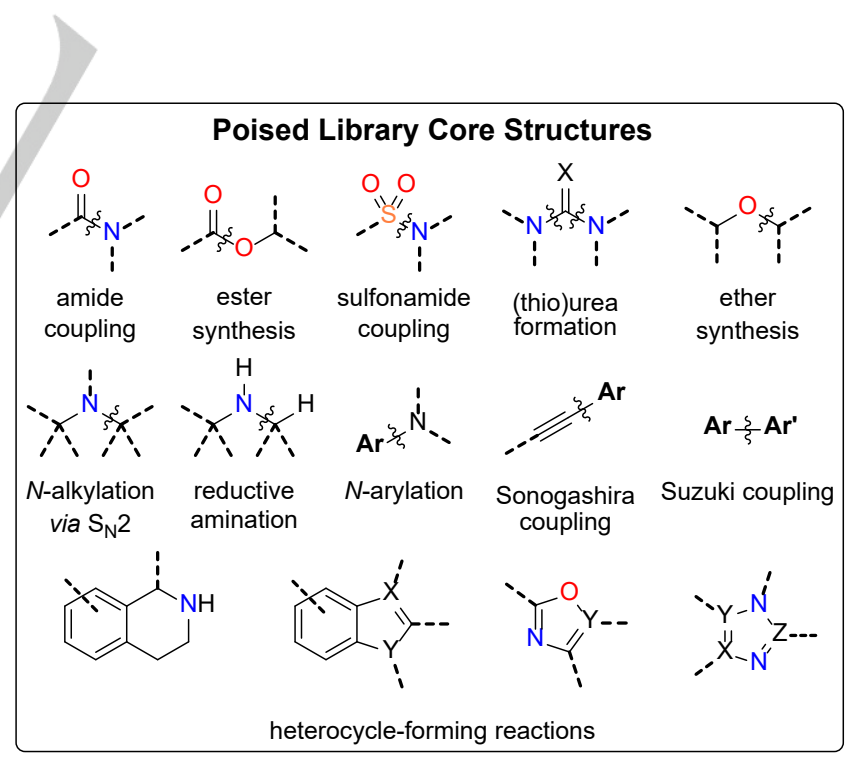

Figure 16. Fragments in the poised library were based on the ten most commonly encountered reactions in drug discovery and twelve heterocycle forming reactions (generic structures shown). Dashed bonds and aromatic groups in bold indicate variable positions depending on the starting materials chosen. ${ }^{[83]}$ 


\section{WILEY-VCH}

\section{MINIREVIEW}

The major downside of applying labelled fragments for either NMR spectroscopy or X-ray crystallography is the limited access to such entities. Both fluorinated and brominated fragment libraries are becoming increasingly available from vendors and provide an easy solution to this challenge. However, such commercial collections typically suffer from low diversity, in particular regarding shape diversity, where most libraries are dominated by flat compounds. Thus, it is recommended to complement such libraries using synthesis and we encourage continued efforts towards such diverse labelled fragments. The same goes for tethering approaches as disulfide-containing fragments are generally not readily available.

For the covalent methods (both reversible and irreversible), another challenge includes ensuring that fragments are of balanced reactivity in order to identify useful non-covalent interactions and not simply the best electrophiles. Covalent fragment methods have so far have only targeted cysteine residues, which are relatively rare. Thus, it would be attractive for future libraries to overcome this limitation by targeting other amino acid side chains as well.

While tdDCC may be an elegant approach, it can be difficult in practice and likely a less suitable technique to implement when designing a new fragment library - at least until more robust analytical methods are developed. To the best of our knowledge, only very few if any attractive chemical leads have been generated using tdDCC. Given that only modest progress has been accomplished over the last decades, it remains to be seen, if this approach will ever be truly practical for FBDD.

In general, screening fragments that can easily be optimized post hit identification is an important and often underappreciated aspect. Thus, no matter which screening methods are selected, this feature should be considered whether deciding on a distinct fragment library or not. However, the poised fragment library ${ }^{[83]}$ does present an exciting approach for FBDD and it would be highly interesting to see more of such libraries, in particular if more shape diverse structures could be accessed as well.

Another approach that we have not touched upon is virtual screening for FBDD. In silico methods are challenged by the many possible binding modes fragments lend themselves to - sorting through these to identify the most promising virtual hits has so far been a serious bottleneck in this area. With the constant improvements to modeling algorithms, it is likely that such approaches will play a larger role in library design in the future not least as more screening data become available to underpin computational approaches. ${ }^{[91,92]}$

\section{Acknowledgements}

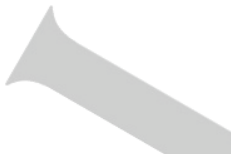

We thank DTU Chemistry for an academic excellence PhD scholarship for N.S.T. We are grateful for support for DKOPENSCREEN from the Ministry of Higher Education and Science (5072-00019B) and from DTU. Figure 3, Figure 8, Figure 10, Figure 12, and Figure 13 were created using BioRender.com.

Keywords: Drug discovery $\cdot$ Ligand design $\cdot$ X-ray crystallography $\cdot$ NMR spectroscopy $\bullet$ Fragment library

[1] W. P. Jencks, Proc. Natl. Acad. Sci. 1981, 78, 4046-4050 [2] D. A. Erlanson, S. W. Fesik, R. E. Hubbard, W. Jahnke, H. Jhoti,
Nat. Rev. Drug Discov. 2016, 15, 605-619.

[3] C. N. Johnson, D. A. Erlanson, C. W. Murray, D. C. Rees, J. Med. Chem. 2017, 60, 89-99.

[4] C. N. Johnson, D. A. Erlanson, W. Jahnke, P. N. Mortenson, D. C. Rees, J. Med. Chem. 2018, 61, 1774-1784.

[5] P. N. Mortenson, D. A. Erlanson, I. J. P. De Esch, W. Jahnke, C. N. Johnson, J. Med. Chem. 2019, 62, 3857-3872.

[6] P. Kirsch, A. M. Hartman, A. K. H. Hirsch, M. Empting, Molecules 2019, 24, 4309.

[7] D. A. Erlanson, I. J. P. De Esch, W. Jahnke, C. N. Johnson, P. N Mortenson, J. Med. Chem. 2020

doi.org/10.1021/acs.jmedchem.9b01581.

[8] G. M. Keseru, D. A. Erlanson, G. G. Ferenczy, M. M. Hann, C. W. Murray, S. D. Pickett, J. Med. Chem. 2016, 59, 8189-8206.

M. J. Harner, A. O. Frank, S. W. Fesik, J. Biomol. NMR 2013, 56, 65-75.

[10] D. A. Erlanson, W. Jahnke, Eds. , Fragment-Based Drug Discovery: Lessons and Outlook, Wiley-VCH, Weinheim, Germany, 2016. M. Congreve, R. Carr, C. Murray, H. Jhoti, Drug Discov. Today 2003, 8, 876-877.

[12] H. Jhoti, G. Williams, D. C. Rees, C. W. Murray, Nat. Rev. Drug Discovery 2013, 12, 644-644

J. Baell, M. A. Walters, Nature 2014, 513, 481-483.

[14] J. B. Baell, G. A. Holloway, J. Med. Chem. 2010, 53, 2719-2740.

[15] G. M. Rishton, Drug Discov. Today 2003, 8, 86-96.

[16] F. Lovering, J. Bikker, C. Humblet, J. Med. Chem. 2009, 52, 67526756 .

[17] A. D. Morley, A. Pugliese, K. Birchall, J. Bower, P. Brennan, N. Brown, T. Chapman, M. Drysdale, I. H. Gilbert, S. Hoelder, et al. Drug Discov. Today 2013, 18, 1221-1227.

[18] S. L. Kidd, T. J. Osberger, N. Mateu, H. F. Sore, D. R. Spring, Front Chem. 2018, 6, 460.

[19] R. Zhang, P. J. McIntyre, P. M. Collins, D. J. Foley, C. Arter, F. von Delft, R. Bayliss, S. Warriner, A. Nelson, Chem. - A Eur. J. 2019, 25 6831-6839.

[20] A. R. Hanby, N. S. Troelsen, T. Osberger, S. L. Kidd, K. T. Mortensen, D. R. Spring, Chem. Commun. 2020, 56, 2280-2283.

[21] C. W. Murray, D. C. Rees, Angew. Chemie - Int. Ed. 2016, 55, 488 492.

[22] S. B. Shuker, P. J. Hajduk, R. P. Meadows, S. W. Fesik, Science 1996, 274, 1531-1534

[23] C. A. Lepre, in Methods Enzymol. (Eds.: J.N. Abelson, M.I. Simon), Elsevier Inc., San Diego, USA, 2011, pp. 220-239.

Elsevier Inc., San Diego, USA, 2011, pp. 220-239.
N. A. Meanwell, J. Med. Chem. 2018, 61, 5822-5880.

C. Dalvit, A. Vulpetti, J. Med. Chem. 2019, 62, 2218-2244.

C. Dalvit, M. Flocco, M. Veronesi, B. J. Stockman, Comb. Chem. High Throughput Screening 2002, 5, 605-611.

[27] T. Tengel, T. Fex, H. Emtenäs, F. Almqvist, I. Sethson, J. Kihlberg, Org. Biomol. Chem. 2004, 2, 725-731.

J. B. Jordan, L. Poppe, X. Xia, A. C. Cheng, Y. Sun, K. Michelsen, H. Eastwood, P. D. Schnier, T. Nixey, W. Zhong, J. Med. Chem. 2012, 55, 678-687.

J. B. Jordan, D. A. Whittington, M. D. Bartberger, E. A. Sickmier, K. Chen, Y. Cheng, T. Judd, J. Med. Chem. 2016, 59, 3732-3749.

A. Vulpetti, U. Hommel, G. Landrum, R. Lewis, C. Dalvit, J. Am. Chem. Soc. 2009, 131, 12949-12959.

[31] A. Vulpetti, C. Dalvit, Drug Discov. Today 2012, 17, 890-897.

[32] S. G. Zech, A. Kohlmann, T. Zhou, F. Li, R. M. Squillace, L. E. Parillon, M. T. Greenfield, D. P. Miller, J. Qi, R. M. Thomas, et al., J. Med. Chem. 2016, 59, 671-686.

[33] A. Vulpetti, S. Randl, S. Rüdisser, N. Ostermann, P. Erbel, A. Mac Sweeney, T. Zoller, B. Salem, B. Gerhartz, F. Cumin, et al., J. Med. Chem. 2017, 60, 1946-1958.

[34] A. Vulpetti, N. Schiering, C. Dalvit, Proteins Struct., Funct., Genet. 2010, 78, 3281-3291.

[35] N. S. Troelsen, E. Shanina, D. Gonzalez-Romero, D. Danková, I. S. A. Jensen, K. J. Sniady, H. Zhang, C. Rademacher, A. Cuenda, C. H. Gotfredsen, et al., Angew. Chem., Int. Ed. 2020, DOI 10.1002/ange.201913125

[36] C. Dalvit, Prog. Nucl. Magn. Reson. Spectrosc. 2007, 51, 243-271. [37] B. M. Johnson, Y. Z. Shu, X. Zhuo, N. A. Meanwell, J. Med. Chem. 2020, DOI: $10.1021 / a c s . j m e d c h e m .9 b 01877$.

[38] F. Manzenrieder, A. O. Frank, H. Kessler, Angew. Chemie - Int. Ed. 2008, 47, 2608-2611.

[39] V. L. Nienaber, P. L. Richardson, V. Klighofer, J. J. Bouska, V. L. Giranda, J. Greer, Nat. Biotechnol. 2000, 18, 1105-1108.

T. L. Blundell, H. Jhoti, C. Abell, Nat. Rev. Drug Discovery 2002, 1, 45-54.

[41] T. G. Davies, I. J. Tickle, in Fragm. Drug Discov. X-Ray Crystallogr. (Eds.: T.G. Davies, M. Hyvönen), Springer, Berling, Heidelberg, 2012, pp. 33-59.

[42] T. Tiefenbrunn, S. Forli, M. Happer, A. Gonzalez, Y. Tsai, M. Soltis, J. H. Elder, A. J. Olson, C. D. Stout, Chem. Biol. Drug Des. 2014, 83, 141-148.

[43] D. J. Wood, J. D. Lopez-Fernandez, L. E. Knight, I. Al-Khawaldeh, C. Gai, S. Lin, M. P. Martin, D. C. Miller, C. Cano, J. A. Endicott, et 
WILEY-VCH

\section{MINIREVIEW}

al., J. Med. Chem. 2019, 62, 3741-3752.

M. O'Reilly, A. Cleasby, T. G. Davies, R. J. Hall, R. F. Ludlow, C. W Murray, D. Tisi, H. Jhoti, Drug Discov. Today 2019, 24, 1081-1086.

[45] G. L. Taylor, Acta Crystallogr. Sect. D Biol. Crystallogr. 2010, 66 325-338

[46] R. Wilcken, X Liu, M. O. Zimmermann, T. J. Rutherford, A. R. Fersht, A. C. Joerger, F. M. Boeckler, J. Am. Chem. Soc. 2012, 134, 6810-6818.

[47] J. Heidrich, L. E. Sperl, F. M. Boeckler, Front. Chem. 2019, 7, 9.

[48] S. V. Ley, A. W. Thomas, Angew. Chemie - Int. Ed. 2003, 42, 5400 5449.

[49] A. Brennführer, H. Neumann, M. Beller, Angew. Chemie - Int. Ed. 2009, 48, 4114-4133.

[50] A. Biffis, P. Centomo, A. Del Zotto, M. Zecca, Chem. Rev. 2018 118, 2249-2295

[51] J. Blaney, V. Nienaber, S. K. Burley, in Fragm. Approaches Drug Discov. (Eds.: W. Jahnke, D.A. Erlanson), Wiley-VCH Verlag GmbH \& Co. KGaA, Weinheim, Germany, 2006, pp. 215-248.

[52] J. D. Bauman, D. Patel, E. Arnold, Top. Curr. Chem. 2011, 317 181-200.

[53] S. A. Hofstadler, K. A. Sannes-lowery, Nat Rev Drug Discov 2006 5, 585-595.

[54] V. V. Hannah, C. Atmanene, D. Zeyer, A. Van Dorsselaer, S. Sanglier-Cianférani, Futur. Med. Chem. 2009, 2, 35-49.

[55] D. A. Erlanson, J. A. Wells, A. C. Braisted, Annu Rev Biophys Biomol Struct 2004, 33, 199-223.

[56] D. A. Erlanson, A. C. Braisted, D. R. Raphael, M. Randal, R. M. Stroud, E. M. Gordon, J. A. Wells, Proc. Natl. Acad. Sci. U. S. A 2000, 97, 9367-9372.

[57] O. Ramström, J. M. Lehn, Nat. Rev. Drug Discovery 2002, 1, 26-36.

[58] D. Screening, M. A. Burlingame, C. T. M. B. Tom, A. R. Renslo, ACS Comb. Sci. 2011, 13, 205-208.

[59] D. M. Turner, C. T. M. B. Tom, A. R. Renslo, ACS Comb. Sci. 2014 16, 661-664.

[60] D. A. Erlanson, J. W. Arndt, M. T. Cancilla, K. Cao, R. A. Elling, N. English, J. Friedman, S. K. Hansen, C. Hession, I. Joseph, et al., Bioorg. Med. Chem. Lett. 2011, 21, 3078-3083.

[61] A. C. Braisted, J. D. Oslob, W. L. Delano, J. Hyde, R. S. Mcdowell, N. Waal, C. Yu, M. R. Arkin, B. C. Raimundo, J. Am. Chem. Soc. 2003, 125, 3714-3715

[62] J. D. Sadowsky, M. A. Burlingame, D. W. Wolan, C. L. Mcclendon, M. P. Jacobson, J. A. Wells, Proc. Natl. Acad. Sci. U.S.A. 2011, 108, 6056-6061.

[63] J. M. Ostrem, U. Peters, M. L. Sos, J. A. Wells, K. M. Shokat, Nature 2013, 503, 548-551.

[64] D. A. Erlanson, J. W. Lam, C. Wiesmann, T. N. Luong, R. L. Simmons, W. L. Delano, I. C. Choong, M. T. Burdett, W. M. Flanagan, D. Lee, et al., Nat. Biotechnol. 2003, 21, 308-314.

[65] M. C. Noe, A. M. Gilbert, in Annu. Rep. Med. Chem., Elsevier, 2012 pp. 413-439.

[66] D. S. Johnson, E. Weerapana, B. F. Cravatt, Futur. Med. Chem. 2010, 2, 949-964.
S. G. Kathman, A. V. Statsyuk, MedChemComm 2016, 7, 576-585. J. Singh, R. C. Petter, T. A. Baillie, A. Whitty, Nat. Rev. Drug Discovery 2011, 10, 307-317. Sethi, P. P. Geurink, A. Aimon, G. Amitai, D. Bellini, et al., J. Am. Chem. Soc. 2019, 141, 8951-8968.

[70] A. Keeley, L. Petri, P. Ábrányi-Balogh, G. M. Keserü, Drug Discov. Today 2020, 10.1016/j.drudis.2020.03.016

[71] R. H. Nonoo, A. Armstrong, D. J. Mann, ChemMedChem 2012, 7, 2082-2086.

[72] S. G. Kathman, Z. Xu, A. V. Statsyuk, J. Med. Chem. 2014, 57 4969-4974.

[73] C. Jöst, C. Nitsche, T. Scholz, L. Roux, C. D. Klein, J. Med. Chem 2014, 57, 7590-7599.

[74] J. Lehn, A. V. Eliseev, Science 2001, 291, 2331-2332.

[75] B. A. Katz, J. Finer-Moore, R. Mortezaei, D. H. Rich, R. M. Stroud, Biochemistry 1995, 34, 8264-8280.

[76] I. Huc, J. M. Lehn, Proc. Natl. Acad. Sci. U. S. A. 1997, 94, $2106-$ 2110.

[77] P. Frei, R. Hevey, B. Ernst, Chem. - A Eur. J. 2019, 25, 60-73.

[78] M. Mondal, N. Radeva, H. Fanlo-Virgós, S. Otto, G. Klebe, A. K. H. Hirsch, Angew. Chemie - Int. Ed. 2016, 55, 9422-9426.

[79] E. C. Y. Woon, M. Demetriades, E. A. L. Bagg, W. Aik, S. M. Krylova, J. H. Y. Ma, M. Chan, L. J. Walport, D. W. Wegman, K. N. Dack, et al., J. Med. Chem. 2012, 55, 2173-2184.

[80] P. Frei, L. Pang, M. Silbermann, D. Eriş, T. Mühlethaler, O. Schwardt, B. Ernst, Chem. - A Eur. J. 2017, 23, 11570-11577.

[81] L. Hoffer, C. Muller, P. Roche, X. Morelli, Mol. Informatics 2018, 37, 1800059.

[82] N. Palmer, T. M. Peakman, D. Norton, D. C. Rees, Org. Biomol. Chem. 2016, 14, 1599-1610.

[83] O. B. Cox, T. Krojer, P. Collins, O. Monteiro, R. Talon, A. Bradley, O. Fedorov, J. Amin, B. D. Marsden, J. Spencer, et al., Chem. Sci. 2016, 7, 2322-2330.

[84] P. Bamborough, M. J. Brown, J. A. Christopher, C. W. Chung, G. W Mellor, J. Med. Chem. 2011, 54, 5131-5143.

[85] H. Chen, Z. Yang, C. Ding, L. Chu, Y. Zhang, K. Terry, H. Liu, Q. Shen, J. Zhou, Eur. J. Med. Chem. 2013, 62, 498-507.

[86] H. Chen, X. Zhou, A. Wang, Y. Zheng, Y. Gao, J. Zhou, Drug Discov. Today 2015, 20,105-113.

[87] G. Karageorgis, D. J. Foley, L. Laraia, H. Waldmann, Nature Chem 2020, 12, 227-235.

[88] J. W.-H. Li, J. C. Vederas, Science 2009, 325, 161-165.

[89] S. Wetzel, R. S. Bon, K. Kumar, H. Waldmann, Angew. Chemie Int. Ed. 2011, 50, 10800-10826.

[90] H. Chen, X. Zhou, Y. Gao, H. Chen, J. Zhou, in Compr. Med. Chem. III (Eds.: S. Chackalamannil, D. Rotella, S.E. Ward), Elsevier, 2017, pp. 212-232

[91] Y. Bian, X. Xie, AAPS J 2018, 20, 59-81.

W. P. Walters, J.Med Chem 2019, 62, 1116-1124. 
WILEY-VCH

\section{Entry for the Table of Contents}
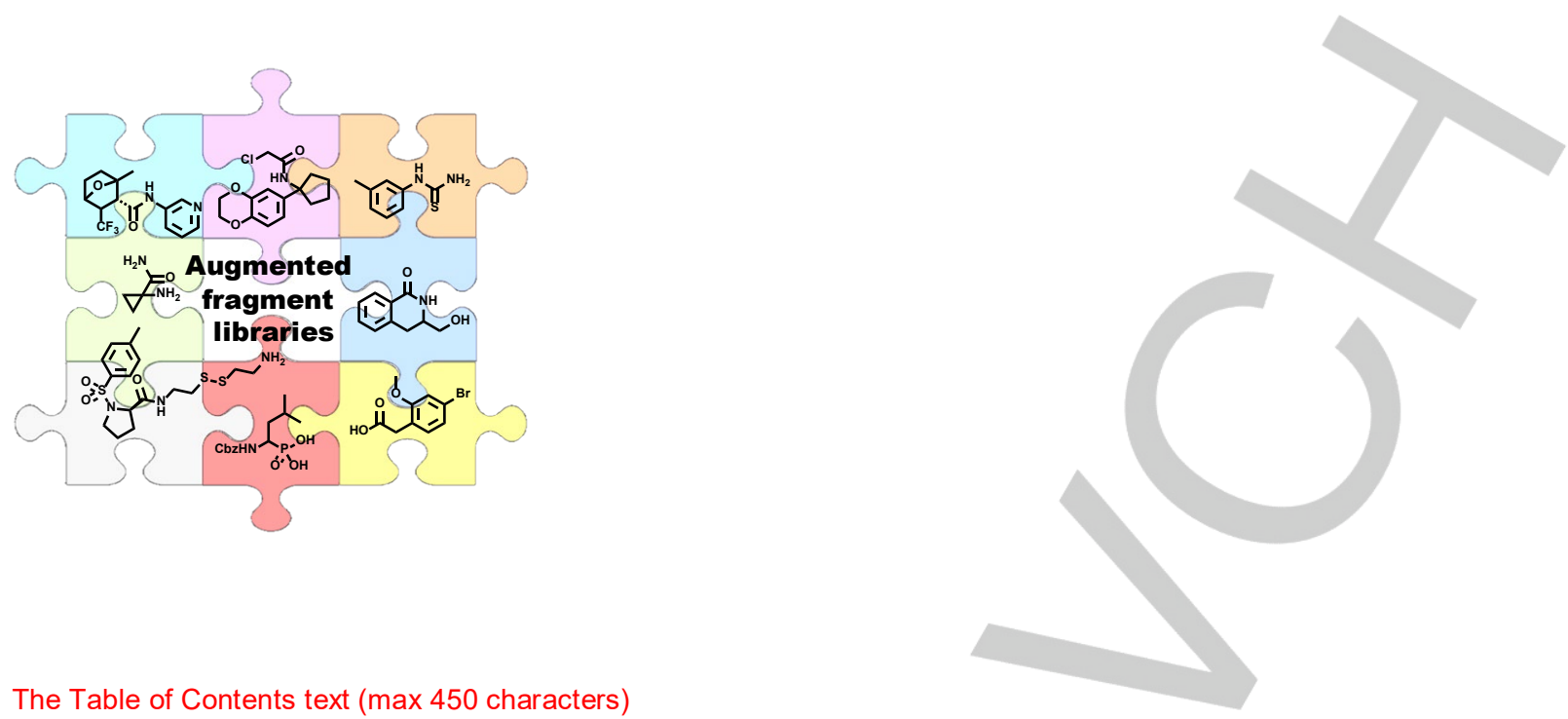

The Table of Contents text (max 450 characters)

Despite the success of fragment-based drug discovery (FBDD), hit-to-candidate progression is not necessarily faster than for highthroughput screening. Thus, technology-driven library design strategies have emerged to facilitate more efficient FBDD. This includes the use of specialized fragments for NMR spectroscopy and X-ray crystallography, covalent linkage for mass spectrometry, dynamic combinatorial chemistry, and optimized fragments. ((The Table of Contents text should give readers a short preview of the main theme of the research and results included in the paper to attract their attention into reading the paper in full. The Table of Contents text should be different from the abstract and should be no more than 450 characters including spaces.)) 